\title{
Case report:management of elective cesarean delivery in the presence of placenta previa and placenta increta
}

\begin{abstract}
Placenta accreta is a placenta implantation that results in an abnormal firm adherence to the uterine wall. ${ }^{1}$ The incidence of placenta accrete is rising due to the growing numbers of cesarean delivery. There is a significant contribution to the maternal morbidity and mortality that leads to postpartum hemorrhage and emergency peripartum hysterectomy. ${ }^{2,3}$ A 31-year-old woman presented for elective cesarean section due to the suspicion of abnormal placental growth, ultrasound examination and magnetic resonance imaging show placental tissue in uterine scar. Delivery time was at $36+2$ weeks of gestation, patient was cared for in the intensive care due to severe blood loss during surgery. The postoperative course was uneventful, and the patient was discharged on day 7 in good conditions.
\end{abstract}

Keywords: Woman, Pregnancy, Diagnostics, Placenta Accrete, Placenta Increte,Cesarean Section, Repeated Cesarean Sections, Baby, Treatment, Hysterectomy
Volume 7 Issue 4 - 2017

\author{
Elina Gelderina,' Inga Vevere, ${ }^{2}$ Evita Lapsane, ${ }^{3}$ \\ Margarita Vasjutenko' \\ 'University of Latvia, Latvia \\ ${ }^{2}$ Riga East University Hospital, Latvia \\ ${ }^{3}$ Department of Obstetrics and Gynecology, Liepaja Regional \\ Hospital, Latvia \\ Correspondence: Elina Gelderina, Faculty of Medicine, \\ University of Latvia, Riga, Latvia, Tel 37 I 29659395, \\ Email elinagelderina@gmail.com
}

Received: June 02, 2017 | Published: July 14, 2017

\section{Introduction}

Placenta accreta is a placenta implantation that results in an abnormal firm adherence to the uterine wall. ${ }^{1}$ There are 3 types of placental pathology - accreta - partial or complete absence of decidua with adherence of placenta directly to the superficial myometrium. Placenta increta extends in the myometrium (invade into whole myometrium) but not through the uterine musculature. ${ }^{4}$ The most severe form of accreta is percreta. In placenta percreta penetration of the trophoblast through the myometrium possibly occurs into the peritoneum and invades adjunct organs and can cause uterine rupture. ${ }^{5}$

Aim: The aim of this article is to present a clinical case in which affordable radiological methods are helping to diagnose serious pathology of the uterus during pregnancy requiring hysterectomy.

\section{Materials and methods}

In this demonstration (case report) we will show you the value of accurate antenatal diagnosis and how these used methods can help and change our treatment strategies.

\section{Case presentation}

A 31-year-old woman (gravida VI, para III) with no concomitant diseases and a history of prior cesarean section due to placenta previa. During pregnancy was made regular $1^{\text {st }}$ and $2^{\text {nd }}$ trimester ultrasonography to rule out fetal pathology and a low-lying or adherent placenta, but the scan did not show any signs of an abnormal placenta or other problems. On admission 13.06.2016 at $3: 15 \mathrm{am}$, the patient presented frequent voiding of urine and pulling abdominal and spinal pain. A day before hospitalization was referred to hospital due to abnormal placentation diagnosed during a routine sonographic examination at $35 / 36$ weeks of gestation. An urgent abdominal ultrasound examination in hospital showed a viable fetus with appropriate biometrical parameters and normal amniotic fluid, while Eco-Doppler images suggested the diagnosis of placenta increta suspecta. Careful evaluation of the placenta with pelvic noncontrast magnetic resonance imaging confirmed the ultrasound diagnosis. The patient was made aware of the potential obstetric complications. An elective cesarean delivery was planned at $36+2$ weeks of gestation. Because she had received spinal anesthesia for her previous cesarean sections, this surgery was also planned with spinal anesthesia. The caesarean surgery was performed as usual. 17.06.2016 at 9:05am a healthy female baby, with weight 2,540 g was delivered. In connection with the diagnosis was made hysterectomy, the resulting material was sent to histological examination. The operation lasted 45 minutes and the patient lost a lot of blood. After all the seams are laid in the pelvic floor was left drain and the abdomen was closed using a regular technique. During the surgery, the patient lost $2000 \mathrm{ml}$ of blood and developed severe hemodynamic instability, with a $10 \%-20 \%$ decrease in systolic blood pressure. A transfusion protocol was initiated. Intraoperative allogeneic red blood cells $(556 \mathrm{ml})$ and free-frozen plasma $(988 \mathrm{ml})$ were transfused. The patient was cared for in the intensive care for one day. The postoperative course was uneventful, and the patient was discharged on day 7 in good conditions. ${ }^{6-8}$
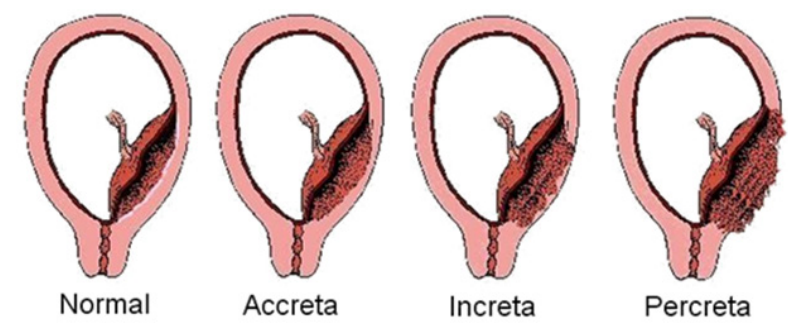

Figure I 3 types of placental pathology.

\section{Conclusion}

Placental pathology is associated with high morbidity and the risk of maternal death, even despite advances in ultrasonographic diagnostics, well-established surgical treatment and multi-disciplinary 
medical care. A rise in the rates of Cesarean section and intrauterine surgical procedure is considered to be the main factor responsible for the growing incidence of placenta accreta. A Cesarean section combined with hysterectomy and application of various techniques to limit massive bleeding is usually performed between 34-36 weeks of pregnancy before the onset of labor. ${ }^{2,4}$

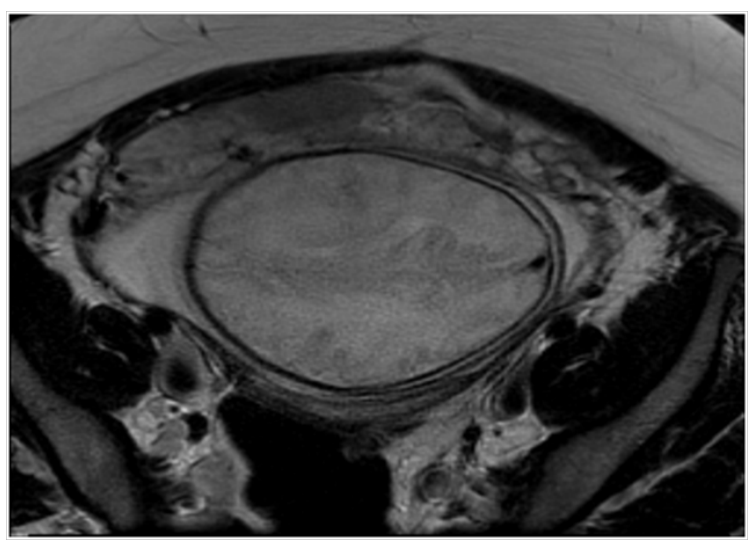

Figure 2 Patients MRI.

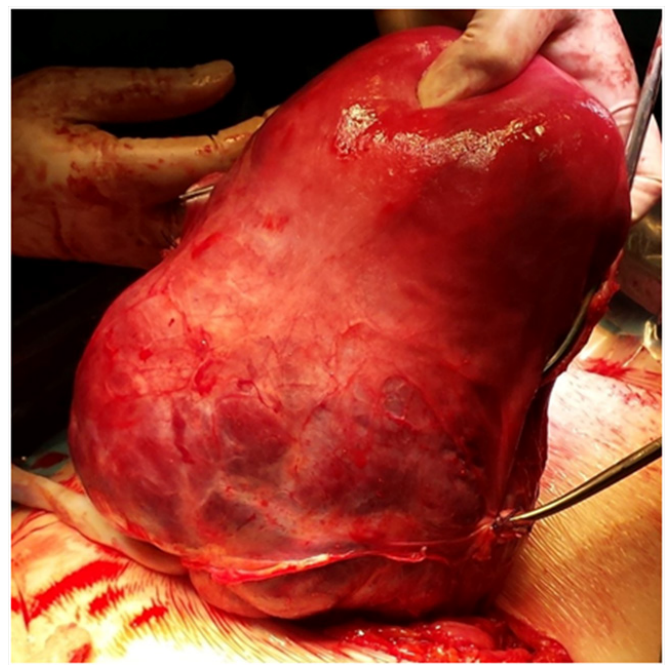

Figure 3 Operation stage, uterus after C-section and before extirpation.

\section{Acknowledgments}

None.

\section{Conflicts of interest}

None.

\section{References}

1. Dahiya P, Nayar KD, Gulati AJ, et al. Placenta Accreta Causing Uterine Rupture in Second Trimester of Pregnancy after in vitro Fertilization: A Case Report. J Reprod Infertil. 2012;13(1):61-63.

2. Bińkowska M, Ciebiera M, Jakiel G. Placenta accreta: review and 3 case reports. Ginekol Pol. 201586(5):396-400.

3. Wong T. Emergency peripartum hysterectomy: a 10-year review in a tertiary obstetric hospital. N Z Med J. 2011;124(1345):34-39.

4. Placenta Accreta.

5. Patricia T Campbell. Critical Care Nursing Clinics of North America. 2017;16(2):231-232.

6. Eller AG, Porter TF, Soisson P, et al. Optimal management strategies for placenta accreta. BJOG. 2009;116(5):648-654

7. Placenta accreta. Committee Opinion No. 529. American College of Obstetricians and Gynecologists. Obstet Gynecol. 2012;120:207-211.

8. Royal College of Obstetricians and Gynaecologists. Placenta praevia, placenta praevia accreta and vasa praevia: Diagnosis and management. Green-top guideline No.27,2011. 